\title{
Relokasi Gempa Low Frequency pada Gunungapi Papandayan menggunakan Optimasi Very Fast Simulated Anneling
}

\author{
Muhammad Mifta Hasan, ${ }^{1, *}$ Hetty Triastuty, ${ }^{2}$ Bagus Jaya Santosa, ${ }^{1}$ dan Amien Widodo ${ }^{3}$ \\ ${ }^{1}$ Jurusan Fisika, Fakultas Matematika dan Ilmu Pengetahuan Alam, \\ Institut Teknologi Sepuluh Nopember (ITS), Kampus ITS Sukolilo, Surabaya 60111 \\ ${ }^{2}$ Pusat Vulkanologi dan Mitigasi Bencana Geologi, \\ Jl. Diponegoro No.57, Cihaur Geulis, Cibeunying Kaler, Bandung 40122 \\ ${ }^{3}$ Jurusan Teknik Geofisika, Fakultas Teknik Sipil dan Perencanaan, \\ Institut Teknologi Sepuluh Nopember (ITS), Kampus ITS Sukolilo, Surabaya 60111
}

\section{Intisari}

Gunungapi Papandayan merupakan gunungapi bertipe stratovolcano dengan aktivitas hidrotermal sebagai aktivitas utamanya yang ditunjukkan dengan adanya aktivitas seismik, salah satunya adalah gempa low frequency (LF). Untuk mengetahui lokasi hiposenter, menggunakan optimasi Very Fast Simulated Anneling (VFSA) yang berbasis random process. Pencarian parameter model didasarkan pada distribusi probabilitas Cauchy yang memungkinkan untuk mendapatkan parameter model yang fit dengan cepat. Hasil relokasi gempa LF pada gunungapi Papandayan menunjukkan bahwa distribusi hiposenter berada di kawasan kawah Mas dan Nangklak dengan kedalaman rata-rata berkisar 0,56 km dengan besar misfit maksimum mencapai 6,4297.

\begin{abstract}
Papandayan which is stratovolcano mountain has high seismic activity especially low frequency event that associate with hydrothermal activity. Calculation of hypocenter used VFSA optimization with basis of random process. Searching of model parameters following Cauchy probability distribution has found the best fit model parameters rapidly. Location of low frequency event at Papandayan volcano concentrate beneath Mas crater and Nangklak crater with around $0.56 \mathrm{~km}$ depth and maximum misfit reach 6.4297 .
\end{abstract}

KATA KUNCI: Low Frequency, Papandayan, VFSA, Mas Crater

\section{PENDAHULUAN}

Gempa low frequency (LF) merupakan salah satu ciri khas dari aktivitas seismik gunungapi Papandayan. Umumnya, gempa LF disebabkan oleh aktivitas hidrotermal khususnya pergerakan fluida yang ada di bawah kawah [1]. Beberapa penelitian telah dilakukan untuk mengetahui lokasi hiposenter dari gempa LF di gunungapi Papandayan. Relokasi gempa LF telah dilakukan oleh Triastuty et al. [2] dengan menggunakan metode Geiger dan Syahbana et al. [3] dengan algoritma 3-D Non-Linier Hypocenter Localization. Untuk memahami lebih jauh distribusi dari hiposenter gempa LF diperlukan metode lain sehingga dapat memastikan bahwa gempa LF berasal dari sumber yang sama. Oleh karena itu, dalam penelitian ini, relokasi dilakukan dengan menggunakan Metode Very Fast Simulated Anneling (VFSA).

Gunungapi Papandayan, secara geografis berada pada $7^{\circ} 19^{\prime} 00^{\prime}$ 'LS dan $107^{\circ} 44^{\prime} 00^{\prime}$ ' BT dengan ketinggian 2665 mdpl. Gunungapi Papandayan mempunyai tipe stratovolkano dengan klasifikasi A, yang termasuk gunungapi aktif [4]. Ben-

*E-MAIL: muhammad.mifta.hasan@gmail.com tuk gunungapi yang tidak teratur, seperti kerucut yang terpotong bagian atasnya, hal ini dipengaruhi oleh perubahan susunan setiap lapisan antara lava dengan aliran debris [5].

Puncak gunungapi Papandayan mempunyai delapan kawah yaitu, Bungbrung, Alun-alun, Parugpug, Papandayan, kawah Mas, kawah Baru, kawah Nagklak dan kawah Manuk. Pada letusan bulan Nopember 2002, terbentuk 4 buah kawah baru. Hanya satu yang tidak terisi, sedangkan yang lain terisi air berwarna hitan dengan bualan lumpur berwarna hijau kebiruan dan terakhir berwarna hijau [6].

Bangunan vulkanik pada kawasan Papandayan tersusun dari batuan lava andesitik tersier yang terakumulasi dari deposit piroklastik dengan lava yang berganti-ganti antara lava basalt dengan andesit [7]. Aktivitas hidrotermalnya ditunjukkan dengan sejumlah manifestasi sulfatara yang mengemisikan asap panas, kolam lumpur sulfatara, mata air panas dengan kandungan asam sulfat dan beberapa lubang kawah yang terletak pada kawah Mas, kawah Manuk, kawah Nangklak dan kawah Baru (Gambar 1). Adanya air yang ada di gunugapi Papandayan (selain magma) sangat menentukan dinamika aktivitas gunungapi Papandayan. Oleh karenanya, gunungapi tersebut dinamai wet volcano gunungapi basah [3].

Struktur geologinya, dipisahkan menjadi struktur sesar dan 




Gambar 1: Lokasi fumarola dan sumber air panas di gunungapi Papandayan. Patahan dan lubang muncul selama letusan november 2002 [7].

struktur kawah. Struktur sesar umumnya berjenis sesar normal, ditemukan di sekitar G. Nangklak, kawah Tegal Alun, kawah Mas dan G. Waliran, serta di lereng baratlaut dan tenggara G. Papandayan, berarah umum NE-SW, NW-SE dan NNW-SSE dengan indikasi berupa breksiasi, kelurusan topografi, zona hancuran struktur kawah, terdapat kawah Mas, kawah Manuk, kawah Brungbrung, kawah Tegal Alun, kawah Nangklak dan kawah Baru.

Gunungapi Papandayan mengalami erupsi terakhir pada tanggal 20 November 2002, yang terjadi di kawah bagian barat laut dengan menghasilkan abu vulkanik hingga mencapai $1500 \mathrm{~m}$ dan awan panas yang mengarah ke timurlaut. Erupsi juga menghasilkan directed blast yang mencapai $2 \mathrm{~km}$ dari kawah dan meninggalkan block dan fragmen dari batuan yang teralterasi. Lubang baru telah terbentuk yang berisi kolam kecil, kolam lumpur dan sumber air panas, yang didominasi oleh fluida dengan kandungan air asam sulfat dan asam sulfat-klorida [7].

Dalam pencarian lokasi hiposenter, digunakan beberapa parameter model yang dicari yaitu posisi hiposenter (dalam koordinat kartesian) dan origin time (waktu munculnya gelombang seismik) dari sumber $\left(\mathrm{x}_{\circ}, \mathrm{y}_{\circ}, \mathrm{z}_{\circ}, \mathrm{t}_{\circ}\right)$. Untuk mendapatkan parameter ini menggunakan persamaan penjalaran gelombang seismik yang terekam pada stasiun perekaman. Diasumsikan gelombang menjalar dalam medium homogen isotropis sehingga penjalarannya berupa garis lurus. Penjalaran ini dirumuskan dalam persamaan [8],

$$
t_{i}=t_{\circ}+\frac{\sqrt{\left(x_{i}-x_{0}\right)^{2}+\left(y_{i}-y_{0}\right)^{2}+\left(z_{i}-z_{0}\right)^{2}}}{v}
$$

dengan $\mathrm{t}_{i}$ adalah waktu tiba gempa yang terekam pada stasiun ke i dan $\mathrm{v}$ adalah kecepatan gelombang seismik dalam medium. Untuk mendapatkan parameter model yang diinginkan, maka dilakukan proses fitting dengan cara menghi- tung waktu tiba menggunakan Pers.(1) dengan memberikan nilai tebakan pada parameter model dan membandingkannya dengan data waktu tiba yang tercatat di masing-masing stasiun. Oleh karena itu, dilakukan proses trial and error dari setiap nilai tebakan. Untuk mempercepat proses ini, dilakukan dengan menggunakan metode VFSA.

\section{METODOLOGI}

Metode VFSA telah digunakan dalam penyelesaian beberapa permasalahan geofisika, misalnya data resistivitas sounding 1-D [9], self-potential [10] dan pemisahan anomali residual data gravity [11]. Dasar dari metode ini merupakan kelanjutan dari metode optimasi Simulated Anneling (SA) yang mana bergantung pada nilai probabilitas tertinggi dari model untuk menggantikan model yang sebelumnya. Pencarian model, dilakukan dengan mencari nilai misfit error terkecil dengan bergerak secara acak dari ruang model. Pergerakan dari pencarian mengikuti distribusi probabilitas Cauchy yang mana mempunyai puncak grafik yang lebih tajam, sehingga dalam metode VFSA ini lebih cepat dan efisien untuk mendapatkan model yang terbaik [9].

Dalam kasus penentuan lokasi hiposenter dari gempa LF di gunungapi Papandayan, digunakan 6 stasiun perekaman data yang tersebar di beberapa titik yaitu, SED, CLL, PAR, TGL, CSR dan GJY. Untuk pencatatan waktu tiba hanya menggunakan waktu tiba dari gelombang $\mathrm{P}$ dengan parameter kecepatan $\left(\mathrm{v}_{p}\right)$ sebesar 2,6 km/s [2]. Pada permulaan perhitungan, dilakukan tebakan parameter model, kemudian menghitung waktu tiba (data sintetik) menggunakan Pers.(1) dan dibandingkan dengan data real yang tercatat pada masingmasing stasiun menggunakan fungsi objektif $(\varphi)$. Dalam penelitian ini, persamaan fungsi objektif dituliskan sebagai berikut,

$$
\varphi=\sqrt{\frac{\overline{(t s-t r)^{2}}}{t r^{2}}} \times 100
$$

dengan ts adalah data sintetik dan tr adalah data real. Pencarian model terbaik dilakukan dari banyaknya jumlah tebakan yang berjumlah 300 kemudian dievaluasi melalui fungsi objektif. Pada saat akan dilakukan update model baru, terlebih dahulu menghitung parameter faktor update $\left(\mathrm{y}_{i}\right)$ yang didasarkan pada distribusi probabilitas Cauchy yang dituliskan sebagai berikut,

$$
y_{i}=\operatorname{sgn}\left(u_{i}-0,5\right) T_{i}\left[\left(1+\frac{1}{T_{i}}\right)^{\left|2 u_{i}-1\right|}-1\right]
$$

yang mempunyai nilai antara $-1 \mathrm{dan}+1$. Pada Pers.(3) variabel $\mathrm{u}_{i}$ merupakan nilai random yang bervariasi antara 0 dan 1. $\mathrm{T}_{i}$ adalah temperatur yang bervariasi setiap perubahan parameter. Masing-masing parameter $\mathrm{P}_{i}$ akan diperbarui dengan model parameter baru $\mathrm{P}_{i}^{(m+1)}$ dari nilai sebelumnya $\mathrm{P}_{i}^{m}$ yang mengikuti persamaan,

$$
P_{i}^{m+1}=P_{i}^{m}+y_{i}\left(P_{i}^{\max }-P_{i}^{\min }\right)
$$




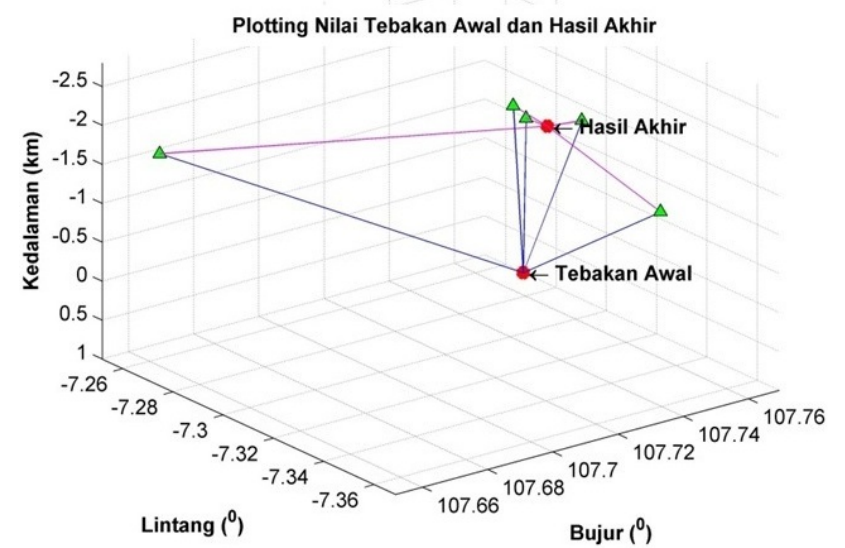

Gambar 2: Perbandingan lokasi hiposenter dari tebakan awal model dengan hasil akhir dan penjalaran sinar gelombang seismik untuk event pada tanggal 07 september 2015 pada jam 08:56:26.42 UTC.

Fungsi objektif untuk model parameter baru dihitung dan dibandingkan dengan model sebelumnya. Jika error dari model baru lebih kecil, maka dipilih model baru dari tebakan yang ada kemudian, dipilih model baru berdasarkan probabilitas $\exp (-\Delta \mathrm{E} / \mathrm{T})$ dengan $\Delta \mathrm{E}$ adalah selisih fungsi objektif dari dua model. Setelah didapatkan model baru, maka dilakukan penurunan temperatur yang mengikuti persamaan,

$$
T_{i}(k)=T_{\circ i} \exp \left(-c_{i} k^{\frac{1}{M}}\right)
$$

dengan $\mathrm{k}$ adalah jumlah iterasi, $\mathrm{c}_{i}$ adalah konstanta, $\mathrm{T}_{\circ i}$ adalah temperature awal, dan $\mathbf{M}$ adalah jumlah parameter model [9]. Dalam penelitian ini, digunakan nilai $\mathrm{c}_{i}=1$ dan $1 / \mathrm{M}$ diganti dengan cs. Nilai temperatur awal $\mathrm{T}_{\circ i}=0,1 ; \mathrm{cs}=$ 0,4 dan menggunakan 500 iterasi. Dari hasil perhitungan didapatkan model baru yang mana pada saat dimasukkan pada Pers.(1) didapatkan selisih perbedaan yang kecil. Ilustrasi hiposenter dari tebakan awal dan hasil akhir dapat dilihat pada Gambar 2. Stasiun perekaman data diilustrasikan dengan bentuk segitiga dengan warna hijau, hiposenter titik warna merah. Penjalaran gelombang untuk hiposenter awal berwarna biru dan penjalaran gelombang untuk hiposenter yang fit berwarna magenta.

Koordinat untuk kedalaman dilakukan dengan bentuk reverse, sehingga untuk lokasi hiposenter yang berada di atas permukaan laut (mdpl) dituliskan dengan lambang negatif. Begitu juga dengan penulisan posisi lintang yang dituliskan negatif untuk bagian selatan khatulistiwa.

\section{HASIL DAN PEMBAHASAN}

Hasil dari penentuan hiposenter menggunakan metode VFSA menunjukkan bahwa distribusi episenter dari gempa LF terpusat di kawasan kawah Mas dan kawah Nangklak yang ditunjukkan pada Gambar 3. Pada gambar tersebut, warna merah menunjukkan posisi dari episenter dan warna biru menyatakan posisi dari seismometer.

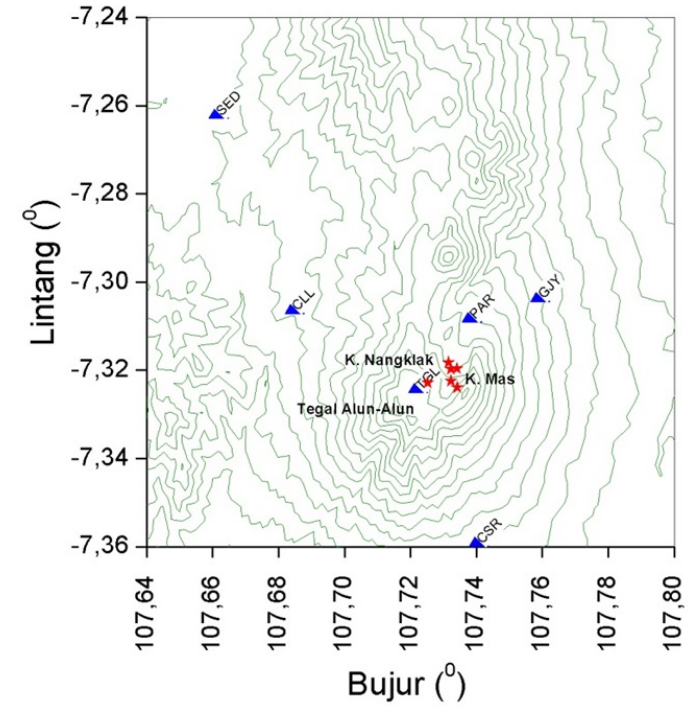

Gambar 3: Distribusi episenter gempa LF di Papandayan.

TABEL I: Parameter model dan nilai misfit untuk masing-masing event.

\begin{tabular}{lcccccc}
\hline Tanggal & & $\begin{array}{c}\text { Lintang } \\
\left({ }^{\circ}\right)\end{array}$ & $\begin{array}{c}\text { Bujur } \\
\left({ }^{\circ}\right)\end{array}$ & $\begin{array}{c}\text { Kedalaman Origin time } \\
(\mathrm{km})\end{array}$ & $\begin{array}{c}\text { Misfit } \\
(\mathrm{s})\end{array}$ & $(\%)$ \\
\hline $1 / 9 / 2015$ & $7: 23$ & $-7,3196$ & 107,7341 & 0,5652 & 9,9747 & 6,4297 \\
$7 / 9 / 2015$ & $8: 56$ & $-7,3224$ & 107,7323 & 0,5654 & 26,4203 & 1,4828 \\
$10 / 9 / 2015$ & $7: 54$ & $-7,3197$ & 107,7323 & 0,5652 & 11,1632 & 0,4674 \\
$10 / 9 / 2015$ & $10: 08$ & $-7,3228$ & 107,7252 & 0,5652 & 44,4265 & 0,9487 \\
$10 / 9 / 2015$ & $12: 55$ & $-7,3182$ & 107,7316 & 0,5664 & 51,7312 & 0,9563 \\
$11 / 9 / 2015$ & $21: 26$ & $-7,3239$ & 107,7342 & 0,7049 & 40,5244 & 1,0536 \\
\hline \hline
\end{tabular}

Penggambaran secara vertikal dapat ditunjukkan dalam bentuk penampang cross-section seperti pada Gambar 4. Dari kedua gambar tersebut dapat disimpulkan bahwa kawah Mas dan kawah Nangklak merupakan kawah yang aktif dengan kawah Nangklak berada di dalam kawasan kawah Mas [2].

Nilai misfit dari perhitungan hiposenter bervariasi, dengan nilai minimum sebesar 0,4674 dan maksimum sebesar 6,4297. Adapun kedalaman dari hiposenter rata-rata berada pada 0,56 km di bawah kawah. Selengkapnya dapat dilihat pada Tabel I.

Nilai misfit yang relatif kecil, dimungkinkan terjadi pada saat penentuan tebakan awal secara acak yang dievaluasi dengan distribusi probabilitas Cauchy, memudahkan dalam pencarian model terbaik dengan iteratif. Distribusi hiposenter yang berkisar pada kedalaman 0,56 km diperkuat oleh Syahbana et al. [3] yang menyatakan bahwa kisaran distribusi hiposenter gempa LF berada pada $0,5 \mathrm{~km}$.

\section{SIMPULAN}

Metode relokasi dengan menggunakan optimasi VFSA dapat menunjukkan hasil yang bagus. Hal ini ditandai dengan besar misfit maksimum mencapai 6,4297. Dari hasil relokasi gempa LF pada gunungapi Papandayan menunjukkan 


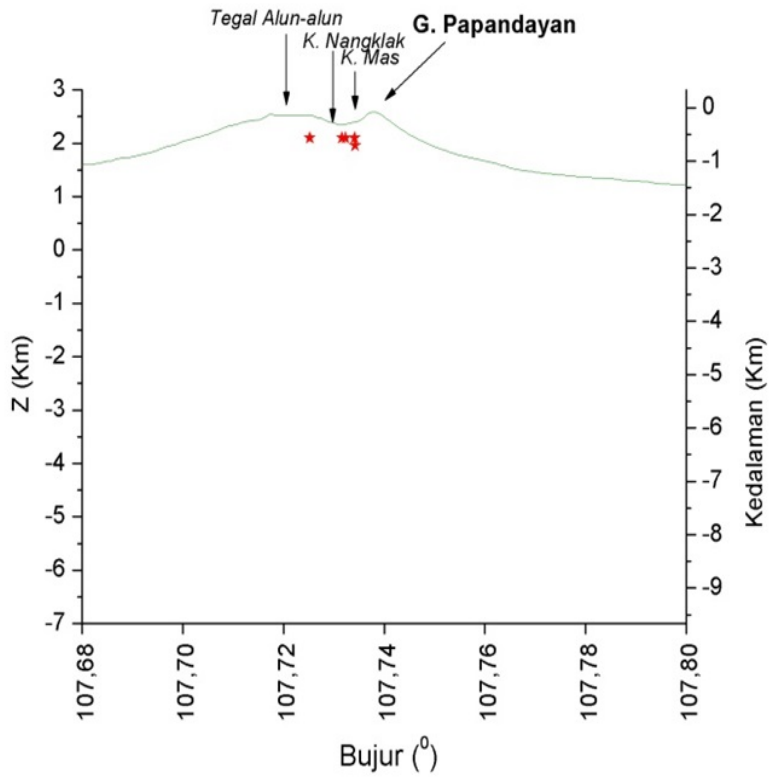

(a)

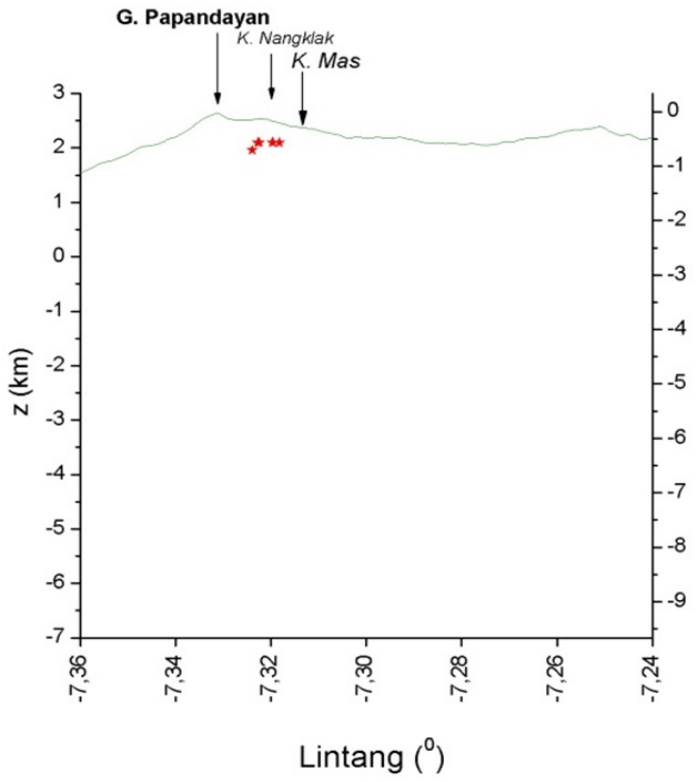

(b)

Gambar 4: Penampang cross-section distribusi hiposenter arah (a) timur-barat, (b) utara-selatan.

bahwa distribusi hiposenter berada di kawasan kawah Mas dan Nangklak dengan kedalaman rata-rata berkisar 0,56 km.

\section{Ucapan Terima Kasih}

Penulis mengucapkan terimakasih kepada PVMBG atas ijinnya dalam menggunakan data aktivitas seismik gunungapi
Papandayan untuk penelitian ini dan penulis juga mengucapkan terimakasih kepada Dr. Sungkono yang membantu dalam pembuatan source code VFSA.
[1] B.A. Chouet, Nature 380, 309-316 (1996).

[2] H. Triastuty, M. Iguchi, T. Tameguri, T., J. Phys., 17, 63-72 (2006).

[3] D.K. Syahbana, et al., J. Volcanol. Geotherm. Res., 280, 76-89 (2014).

[4] PVMBG, Data Dasar Gunung Api, Badan Geologi, Bandung, 2013.

[5] H.Z. Abidin, et al., Deformation Monitoring of Indonesian Volcanoes Using Repeated GPS Survey Method: Status and Plan, Proceeding of Symposium on Japan-Indonesia IDNDR Project Volcanology, Tectonics, Flood and Sediment Hazards, September 21-23, Bandung, Indonesia, 1998.
[6] Kristianto, Studi Seismik Tomografi Pada Kasus Gunungapi Papandayan, Thesis, Institut Teknologi Bandung, 2005.

[7] A. Mazot, et al., J. Volcanol.Geotherm. Res., 178, 276-286 (2008).

[8] T. Lay, and T.C. Wallace, Modern Global Seismology (Academic Press, San Diego, 1995).

[9] S.P. Sharma, Computers \& Geosciences, 42, 177-188 (2012).

[10] A. Biswas, and S.P. Sharma, Journal of Applied Geophysics, 105, 235-247 (2014).

[11] A. Biswas, Geoscience Frontiers, 6, 875-893 (2015). 